\title{
Permeability of the capillaries of the cardiac muscle after intramyocardial perfusion of macromolecular solutions
}

\author{
PANAGIOTIS C. PETROPOULOS \\ From the Department of Surgery I of the Medical Faculty, \\ University of Göteborg, Sweden
}

It is generally believed that the anatomical capillary wall (Landis, 1927 ; Wissig, 1958), or even the 'haematolymph barrier' that may surround it (Sapirstein, 1959), is relatively impermeable to macromolecules. This opinion cannot be accepted with regard to the capillaries of all the organs (Petropoulos, 1963). It is, for example, well known that gamma globulin cannot be synthesized in the foetus at all. Although it has a molecular weight twice that of albumin, it can be selectively transferred across the capillaries in the placenta, to such an extent that there is no more gamma globulin in the foetal blood than in the maternal blood (Moore, 1959 ; Moore and Ruska, 1957). It should be mentioned that the placental capillaries have a structure similar to that of the capillaries in other organs. On the other hand, it is known that heart muscle is able to 'absorb' extravascular blood in much larger quantities than skeletal muscle, owing to its particular vascular structure (Sabiston, Fauteux, and Blalock, 1957). In previous experiments we showed that direct perfusion of heparinized blood to the normal ischaemic ventricular myocardium at a rate of $2 \mathrm{ml}$. per minute was possible if the perfusion pressure was steadily increased. The animals could tolerate such a perfusion for eight to 26 minutes without a significant change of rhythm or pressure. Further perfusions at the same rate led to an irregularity of the rhythm with a gradual decrease in the systemic pressure until fibrillation finally occurred. A large haematoma surrounding the perfusing tube was found on each occasion. Perfusion of low molecular weight dextran to the ischaemic myocardium at a rate of $4 \mathrm{ml}$. per minute could, however, be tolerated for a longer period (Petropoulos, 1963), during which time the systemic pressure increased to a level approaching normal. After 60 minutes' perfusion the heart was excised. The predicted heart weight (Herrmann, 1925) was not found to be increased after an intramyocardial perfusion of
$240 \mathrm{ml}$. dextran. These findings have proved that a selective capillary permeability to the heart muscle exists even for dextran of 40,000 molecular weight.

The permeability of the myocardial blood capillaries to macromolecular solutions perfused in the heart muscle has been studied with regard to molecular weight values and perfusing pressures.

\section{METHODS AND RESULTS}

Young unselected mongrel dogs weighing from 10 to $19 \mathrm{~kg}$. were used. Anaesthesia was induced and continued with intravenous nembutal, $25 \mathrm{mg}$. $/ \mathrm{kg}$.; cyclic positive pressure insufflation of the lungs with room air was maintained, and the thorax was opened through the sixth left intercostal space. The pericardium was widely opened and a No. 18 Rochester needle with multiple perforations of the distal $2 \mathrm{~cm}$. was inserted in the anterior surface of the wall of the apex of the heart for a distance of 2.5 to $3 \mathrm{~cm}$. in the direction of its longitudinal axis, $2 \mathrm{~cm}$. left lateral of the anterior descending coronary artery and 3 to $4 \mathrm{~mm}$. under the epicardium. The tissues surrounding the entrance of the plastic cuff of the needle were tightly closed with some drops of Eastman adhesive (Carton, Kessler, Seidenberg, and Burwith, 1960). One femoral artery was cannulated, and pressures were continuously recorded. From some previous experiments we knew that normotonic glucose solutions or dextran of 40,000 molecular weight could easily be perfused in any region of the ventricular myocardium of the beating heart at a rate of $4 \mathrm{ml}$. per minute and a perfusion pressure level of about 130 to $200 \mathrm{~mm}$. $\mathrm{Hg}$. During perfusion at the above rates the regional coronary vessels were not macroscopically distended (Petropoulos, 1963). When 5 to $7 \mathrm{ml}$. was rapidly perfused in 2 to 3 seconds under higher pressure the regional veins suddenly distended and their contents became whitish. This phenomenon was much more noticeable when a concentration of $7 \%$ India ink was added to the rapidly perfused solution, after which the distended veins of the anterior interventricular groove became blue in 
colour. The veins were macroscopically distended to the base of the heart. The veins filled so quickly that, even with a high-speed cinematographic film, taken at the beginning of the sudden intramyocardial perfusion, the beginning of the distension and colorization of the great cardiac veins could not be seen. Only the gradual filling of the side branches of the veins was visible.

In each dog one only of the following solutions, in a gradually increased molecular weight, was rapidly perfused to the left ventricular myocardium in 2 to 3 seconds:

(a) glucose (180 molecular weight) $5 \%$ in water.

(b) urographin $(635.8$ molecular weight) $60 \%$.

(c) low molecular weight dextran (Rheomacrodex) (40.000 molecular weight),

(d) haemolysed blood (68.000 molecular weight) with 10) distilled water,

(e) plain blood $( \pm 75.000$ molecular weight $)$ containing $5 \mathrm{ml}$. per $1,000 \mathrm{ml}$. heparin.

Fresh water solutions of $7 \%$ India ink, the particles of which were about the same size as erythrocytes, were mixed in a proportion of $1: 10$ with the glucose, dextran, and haemolysed blood.

The perfusion was done manually with a $20 \mathrm{ml}$. syringe connected by a cannula with a No. 18 Rochester needle which had previously been inserted in the myocardium. A side cannula was connected to an electromanometer, and the perfusion pressure was recorded. A perfusion pressure of about $250 \mathrm{~mm}$. $\mathrm{Hg}$ was required when glucose was perfused ; $280 \mathrm{~mm}$. $\mathrm{Hg}$ with urographin ; $350 \mathrm{~mm}$. $\mathrm{Hg}$ with dextran; $800 \mathrm{~mm}$. $\mathrm{Hg}$ with haemoglobin; and $920 \mathrm{~mm}$. $\mathrm{Hg}$ with plain blood. During and after the perfusion, extrasystoles appeared, and the systemic pressure decreased (Table). These effects on the heart function were accelerated and lasted much longer when haemoglobin or plain blood was perfused (Fig. 1). In all our experiments the veins of the anterior interventricular groove and their branches were distended and coloured when India ink was present in the perfused fluid (Fig. 2). However, this distension occurred more slowly when haemoglobin or plain blood was perfused. Urographin $60 \%$ was injected in 3 seconds into the anterior wall of the apical myocardium as above, and cineangiocardiographic pictures were taken during the injection. The contrast material appeared successively in two parallel vessels in the region of the anterior interventricular groove. Similar vessels were seen on the posterior surface of the heart. All the vessels described gained direct communication with a broad vessel corresponding to the coronary sinus. as judged from its position and appearance. In the last picture a contrast depot was still present in the injected region of the left ventricular myocardium (Fig. 3). Specimens of the myocardium for electronmicroscopic examination were taken from several regions of the anterior interventricular groove at varying distances from the perfused area.

In several microsections India ink particles were visible in the lumen of the capillaries and in the interstitial spaces. It was not possible to locate the anatomical features through which capillary penetration of the India ink macromolecules had taken place.

In order to study the possibility of macroscopical visualization of the same vessels over a greater distance. $20 \mathrm{ml}$. of India ink in dextran was perfused. with the above technique, in the beating heart of a calf weighing $42 \mathrm{~kg}$., and $20 \mathrm{ml}$. thorotrast in the heart of a second calf weighing $62 \mathrm{~kg}$. The great cardiac veins again filled as before. Specimens of the myocardium from the anterior interventricular groove taken as before showed the same findings.

These fluids and solutions were perfused with the same technique and pressures in freshly excised dog and calf hearts. Immediate distension and visualization of the same veins as before were evident (Fig. 4).

In order to compare the extent of diffusion of radiopaque dyes injected with the same technique and pressures simultaneously into the heart and several

T A B LE

\begin{tabular}{|c|c|c|c|c|c|c|c|c|c|c|c|}
\hline \multirow{2}{*}{$\begin{array}{c}\text { Weight } \\
\text { (kg.) }\end{array}$} & \multirow{2}{*}{$\begin{array}{l}\text { Pressure } \\
\text { before } \\
\text { Perfusion } \\
(\mathrm{mm} . \mathrm{Hg})\end{array}$} & \multicolumn{2}{|c|}{ Perfusion } & \multicolumn{7}{|c|}{$\begin{array}{c}\text { Systemic Pressure (mm. Hg) } \\
\text { After Perfusion (min.) }\end{array}$} & \multirow[b]{2}{*}{60} \\
\hline & & $\begin{array}{l}\text { lime } \\
\text { (sec.) }\end{array}$ & $(\mathrm{mm} . \mathrm{Hg})$ & Immediate & 1 & & 5 & 15 & 30 & 45 & \\
\hline $\begin{array}{c}\text { Glucose a } \\
12 \\
12\end{array}$ & $\begin{array}{l}\text { ind India Ink } \\
140100 \\
12090\end{array}$ & $\begin{array}{l}2 \\
2\end{array}$ & $\begin{array}{l}250 \\
245\end{array}$ & $\begin{array}{l}13595 \\
11390\end{array}$ & $\begin{array}{l}1 3 5 \longdiv { 9 0 } \\
11590\end{array}$ & & $\begin{array}{l}135 / 95 \\
11790\end{array}$ & $\begin{array}{l}140: 100 \\
12090\end{array}$ & $\begin{array}{l}140100 \\
12090\end{array}$ & $\begin{array}{l}140: 100 \\
12090\end{array}$ & $\begin{array}{l}140100 \\
12090\end{array}$ \\
\hline $\begin{array}{c}\text { Dextran } \\
11 \\
10\end{array}$ & $\begin{array}{l}\text { and India Ink } \\
150 / 120 \\
135 / 105\end{array}$ & $\begin{array}{l}2 \\
2\end{array}$ & $\begin{array}{l}358 \\
350\end{array}$ & $\begin{array}{l}10585 \\
11090\end{array}$ & $\begin{array}{l}10585 \\
11090\end{array}$ & | & $\begin{array}{l}10585 \\
11090\end{array}$ & $\begin{array}{l}105: 85 \\
11090\end{array}$ & $\begin{array}{l}10585 \\
11090\end{array}$ & $\begin{array}{l}10585 \\
11290\end{array}$ & $\begin{array}{l}10790 \\
11590\end{array}$ \\
\hline $\begin{array}{c}\text { Urograph } \\
19\end{array}$ & $\left.\right|^{i n} 150^{\prime} 120$ & 3 & 280 & 115100 & $115 / 90$ & $\mathrm{i}$ & 11590 & 11590 & 11590 & 12095 & 12095 \\
\hline $\begin{array}{c}\text { Haemoly } \\
11 \\
10\end{array}$ & $\begin{array}{l}\text { sed Blood and } \\
125 / 105 \\
12090\end{array}$ & $\begin{array}{c}\text { India } \\
3 \\
3\end{array}$ & $\begin{array}{r}\text { Ink } \\
805 \\
800\end{array}$ & $\begin{array}{l}75: 60 \\
78: 65\end{array}$ & $\begin{array}{l:l}75 & 60 \\
78 & 65\end{array}$ & & $\begin{array}{l}75: 60 \\
78: 65\end{array}$ & 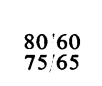 & $\begin{array}{l}80: 60 \\
75 / 65\end{array}$ & $\begin{array}{l:l}80 & 60 \\
75 & 65\end{array}$ & $\begin{array}{l:l}80 & 65 \\
75 & 65\end{array}$ \\
\hline $\begin{array}{c}\text { Plain Blc } \\
12 \\
11 \cdot 5\end{array}$ & $\begin{array}{ll}135 / 110 \\
10085\end{array}$ & $\begin{array}{l}3 \\
3\end{array}$ & $\begin{array}{l}920 \\
918\end{array}$ & $\begin{array}{l}7750 \\
6245\end{array}$ & $\begin{array}{l}65 / 45 \\
62 / 45\end{array}$ & 1 & $\begin{array}{l}65 / 45 \\
62 / 45\end{array}$ & $\begin{array}{l}65 / 50 \\
65 / 45\end{array}$ & $\begin{array}{l}70 / 50 \\
65 / 45\end{array}$ & $\begin{array}{l}70 / 50 \\
65 / 45\end{array}$ & $\begin{array}{l}75 / 50 \\
65 / 45\end{array}$ \\
\hline
\end{tabular}




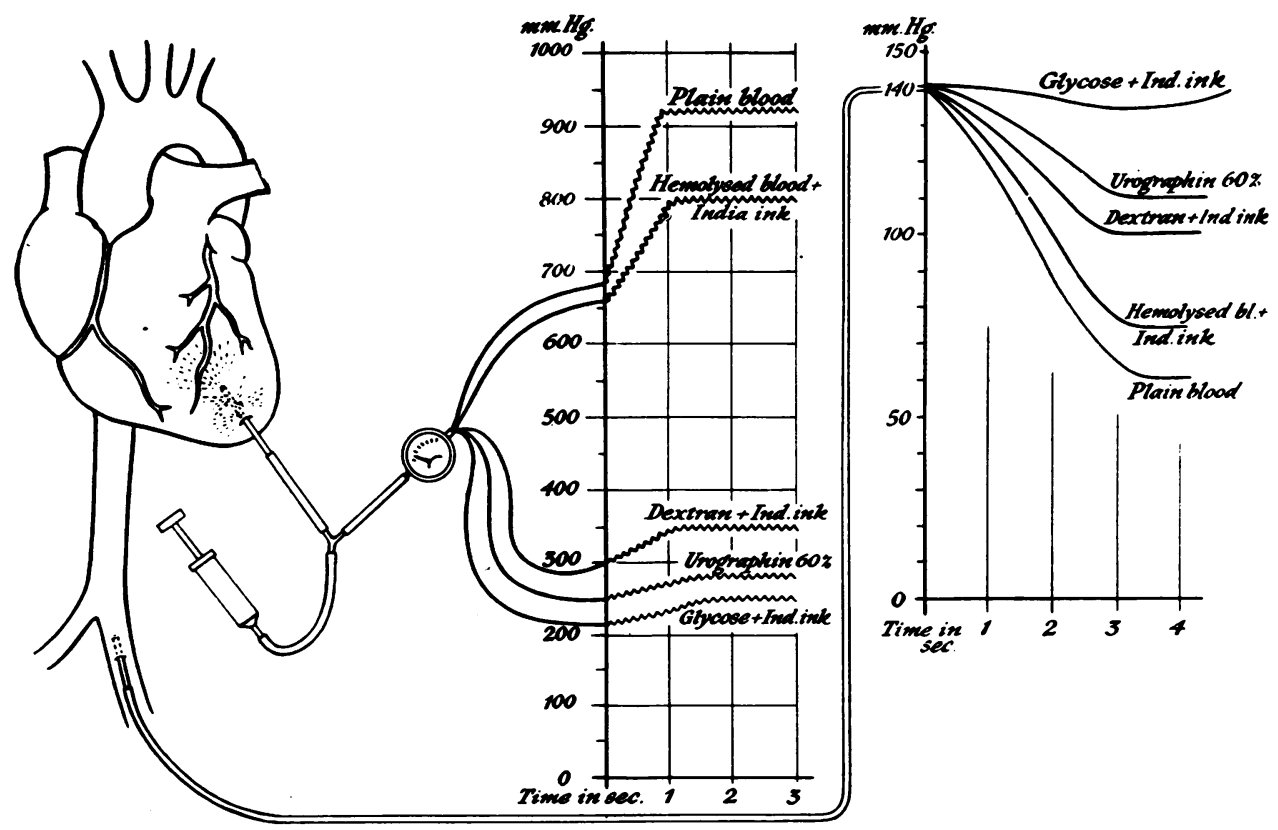

FIG. 1. Presents graphically (a) the stepwise increase of the perfusion pressure with the increased molecular weight of the perfused fluid, and (b) the stepwise decrease of the systemic pressure with the increased molecular weight of the perfused fluid.
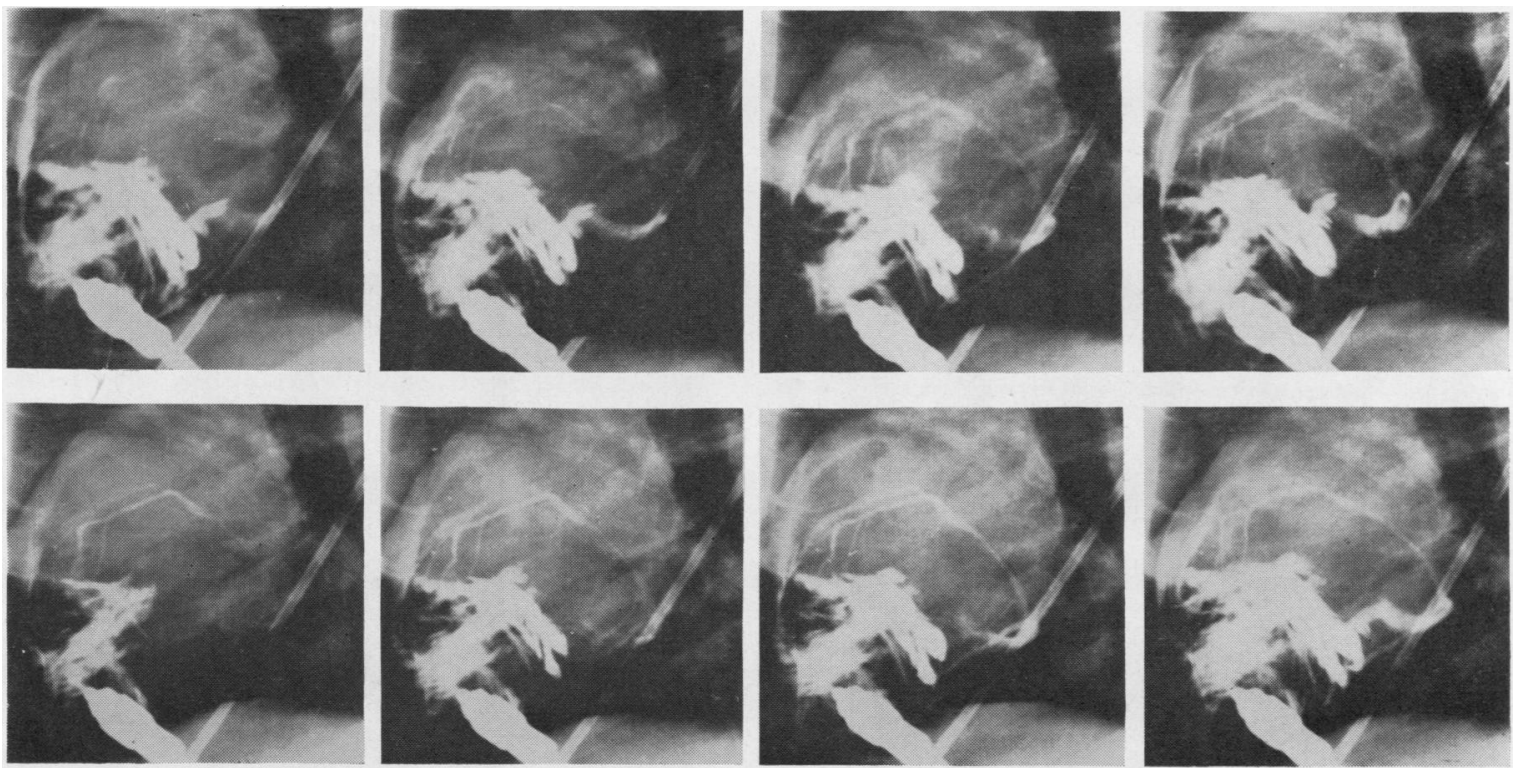

FIG. 3. Gradual appearance of the contrast material in two parallel vessels, located in the region of the interventricular groove and the posterior surface of the heart, gaining communication to a broad vessel corresponding to the coronary sinus. $A$ contrast depot is seen in the injected area at the apex. 


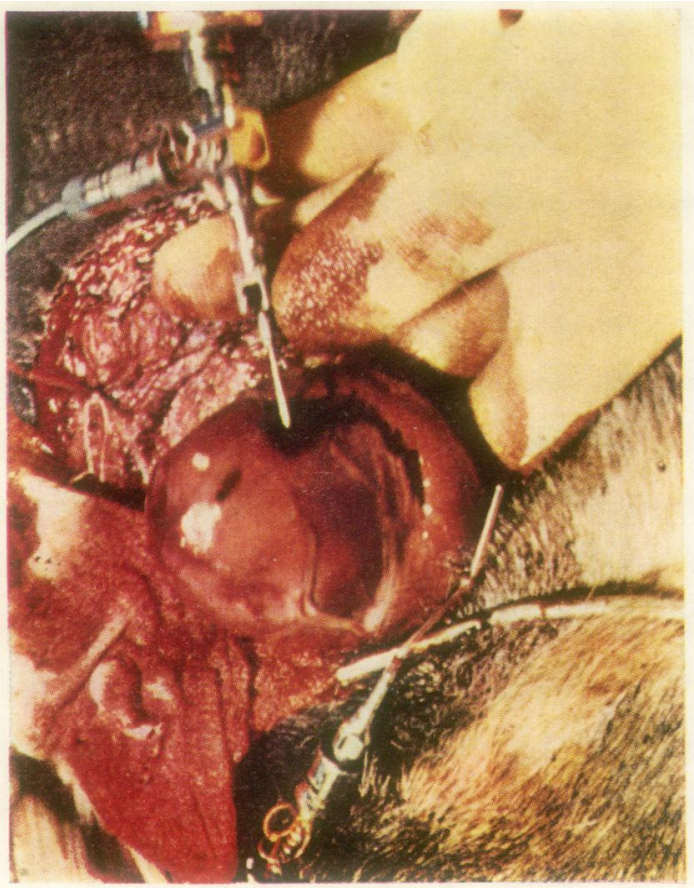

(a)

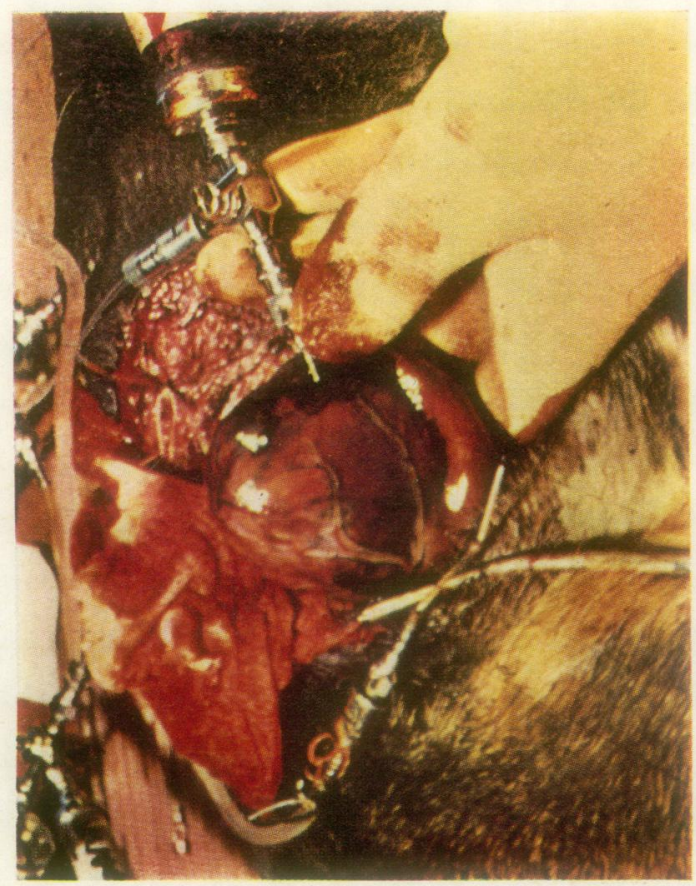

(c)

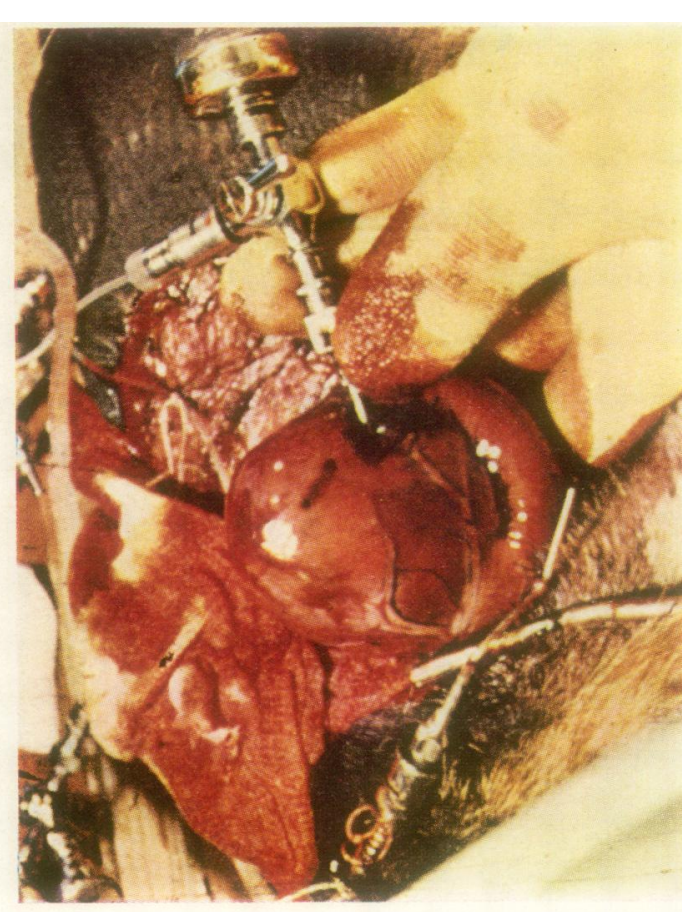

(b)

FIG. 2. Cinematographic pictures of the anterior surface of the beating heart during sudden intramyocardial perfusion of a solution of India ink in dextran showing rapid filling and colorization of the great cardiac veins and their branches. 


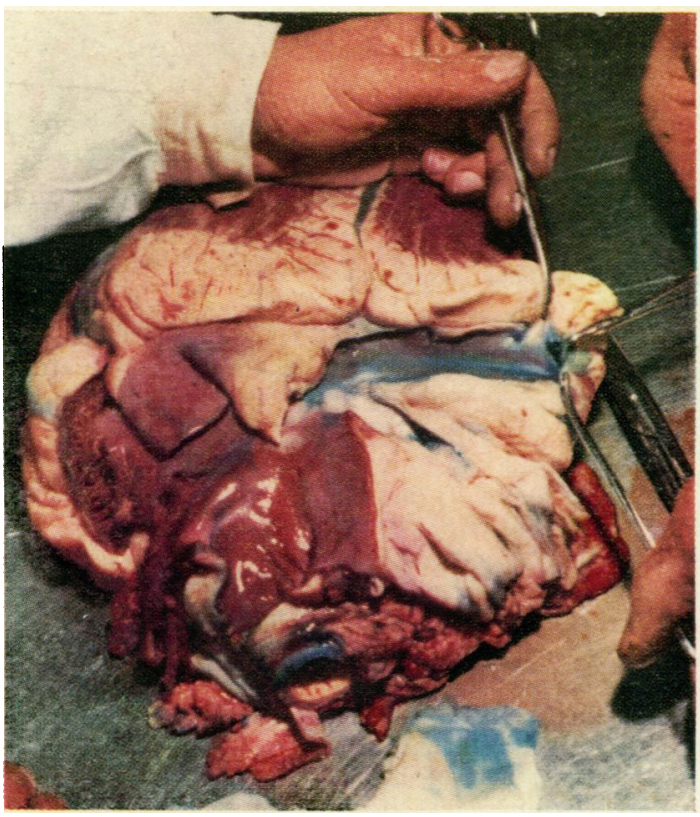

FIG. 5. The whole heart becomes fluorescent six minutes after the perfusion of $10 \mathrm{ml}$. fluorescein in dextran to the left ventricular myocardium.

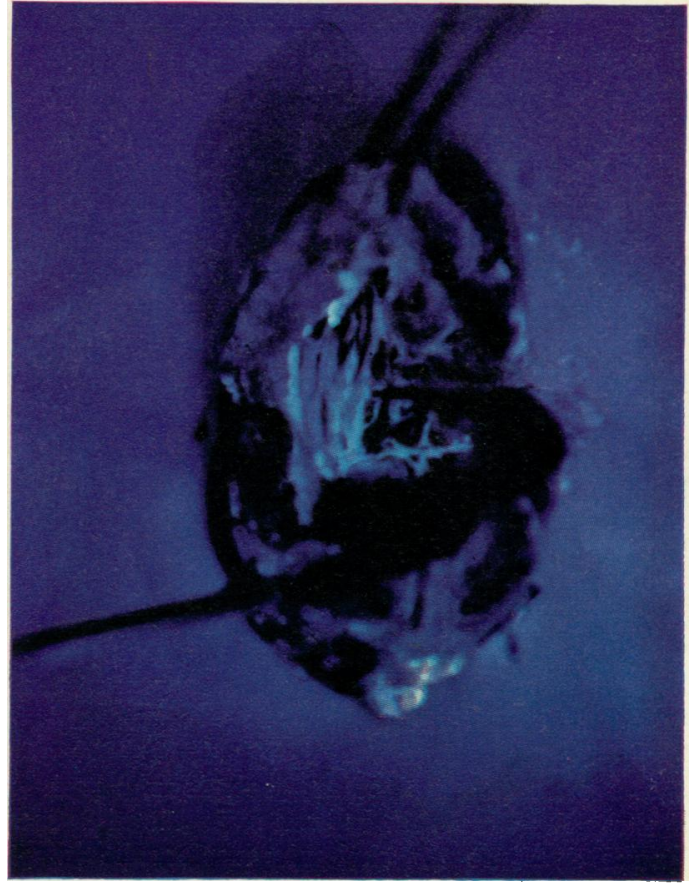

FIG. 6. Transverse sections of the heart show a fluorescence of the myocardium, endocardium, and even of the valves. 
skeletal muscles of dogs, urographin $60 \%$ was perfused under a pressure of $280 \mathrm{~mm}$. $\mathrm{Hg}$ from a syringe connected by a $Y$ connexion to the two perfusing cannulae. During perfusion the contrast material appeared immediately in the great cardiac veins, but only a contrast depot was formed in the skeletal muscles.

The capillary permeability to fluorescein has been studied in two more dog hearts and the heart of a horse weighing $1,600 \mathrm{~g}$. Immediately after sacrifice the hearts were excised and washed carefully with cold water. Ten millilitres of a $5 \%$ solution of fluorescein in dextran of 60,000 molecular weight was rapidly perfused to the apex in one of the dog hearts, as before, and to the middle of the posterior surface of the left ventricular myocardium 3 to $4 \mathrm{~mm}$. under the epicardium in the other heart. In the apex of the horse heart $30 \mathrm{ml}$. of the same solution was rapidly perfused. The perfusion wound was sealed with Eastman's adhesive. Six to 11 minutes after the perfusion the surfaces of both hearts became fluorescent (Fig. 5). Multiple transverse sections of the hearts have shown that not only the myocardium but even the endocardium and the valves become fluorescent (Fig. 6). Injection of the same amount of fluorescein $4 \mathrm{~mm}$. under Glisson's capsule of the liver in the same animals did not result in a diffusion of the fluorescent dye outside the perfused region.

\section{DISCUSSION}

From the above experiments it was impressive to find that myocardial capillary permeability was evident after the injection of lipid insoluble particles of low molecular weight, such as glucose and urographin, as well as those of higher molecular weight, such as dextran, haemoglobin, and even plain blood. With the exception of the injected plain blood and urographin, each of the above substances contained $7 \%$ India ink.

The tabulated figures for capillary permeability of the skeletal muscle (Wissig, 1958; Pappenheimer, 1953 ; Pappenheimer, Renking, and Borrero, 1951 ; Pappenheimer and Soto-Rivera, 1948) indicate zero permeability to haemoglobin, i.e., haemoglobin is not able to pass their capillary membranes. However, the presence of haemoglobin in the lymph proves that there is some permeability of these capillaries. The size of the haemoglobin large molecules which are able to penetrate the capillaries may be taken as an estimate of the size of the largest pores present in the capillary wall (Renking, 1954 ; 1959). When we injected macromolecular solutions, such as dextran, haemoglobin or even plain blood or radiopaque dye into the skeletal muscles, the injected fluids remained concentrated in the perfused region, at least initially. When the same fluids were perfused under the same pressure into the myo- cardium, they were immediately visible in the regional veins. These experiments prove that the wall of the myocardial capillaries has some specific properties as regards the rate of penetration of substances which do not penetrate the capillary wall of other organs in considerable quantities. By electronmicroscopic studies we tried to determine the anatomical features through which this selective coronary permeability takes place. We hoped to locate the exact route of penetration of the India ink particles, at least through the capillary membranes. Unfortunately, details of the course of penetration were not visible in our electronmicroscopic studies.

The term 'capillary clearance' is used in the literature to express the rates at which various substances are transported from the capillaries to the tissues (Zweibach, 1959). We suggest that the term 'tissue clearance' be used as a convenient means of expressing the rates at which various substances are transported from the tissues to the capillaries. The tissue clearance should depend on the molecular weight of the perfused fluid, the degree of local increase of the post-perfusion interstitial pressure, the anatomical density of the capillary structure, and the continuous contraction of the muscles surrounding the region of the perfused tissues. The density per square millimetre of the myocardial capillaries is known to be at least double that of the skeletal muscles (Anrep, Blalock, and Hammouda, 1929; Martin, Wooley, and Miller, 1932 ; Gregg, 1950 ; and Mautz, 1957). The presence of several supplementary paths of circulation within the heart, such as the Thebesian and Vieussens' systems, should further increase the tissue clearance of the myocardium. The continuous contraction of the heart muscle should also contribute to the tissue clearance.

Undisturbed regional blood flow is known to be an important factor in determining the rates of transcapillary exchange. This factor cannot be expected to interfere with tissue clearance, especially when fluids of higher molecular weight, such as haemoglobin or plain blood, have been perfused into the myocardium. Because it is difficult for such large molecules or blood cells to penetrate the capillary wall, a sudden accumulation occurs in the interstitial spaces of the myocardium, causing a tamponade of the surrounding capillaries (Fig. 7). The coronary blood flow is then locally diminished, and this creates a regional myocardial ischaemia with all its consequences. In each of our experiments in which fluids of high molecular weight were suddenly perfused into the myocardium, the systemic pressure decreased imme- 


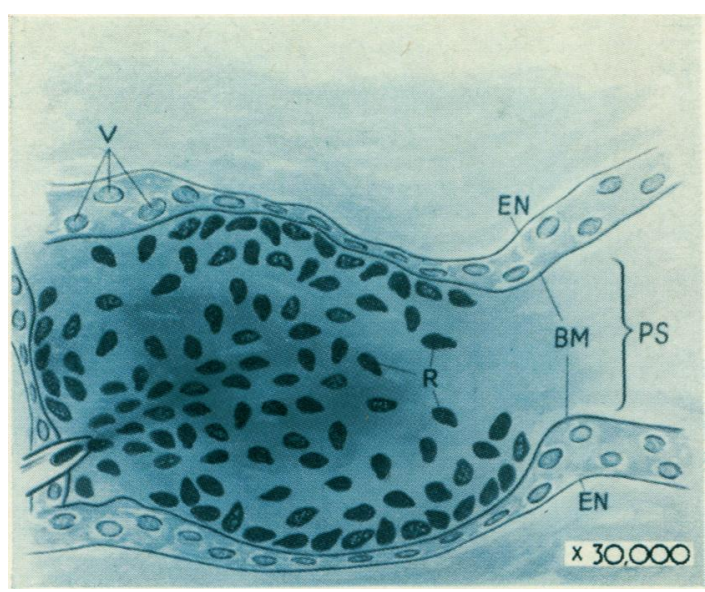

FIG. 7

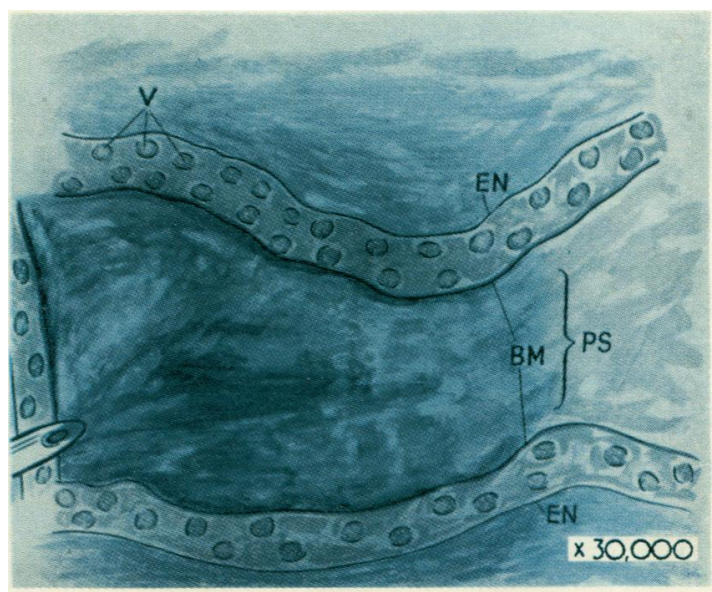

FIG. 8

FIG. 7. Blood cells and large serum albumin molecules of heparinized plain blood perfused into the myocardium have accumulated in the interstitial spaces, producing a tamponade of the wall of the capillaries.

FIG. 8. Easy penetration of glucose containing a small concentration of India ink through the wall of the myocardial capillaries. $B M=$ basement membrane; $E N=$ endothelial tunic; $V=$ vesicles of the endothelial cell; $P S=$ pericapillary space; $R=$ red blood cells; $P S=$ pericapillary space.

diately and dense extrasystoles appeared and persisted for a long time. On the other hand, when the same amounts of fluids of low molecular weight, such as glucose containing only a small concentration of India ink $(2 \%)$, were injected, a tamponade of the surrounding capillaries either did not occur (Fig. 8) or was only transitory in that the resulting decrease of systemic pressure was negligible and the extrasystoles were fewer and disappeared more quickly.

It may also be concluded that restriction of the regional coronary flow due to a local increase of the interstitial tissue pressure did not prevent immediate tissue clearance. We therefore suggest that post-perfusion tissue clearance is a process which may take place through normal epithelium basement membranes and mainly through the potential spaces between cells. These spaces may be permeable under certain conditions, as, for example, when the physical forces which normally maintain the connexion of cells are removed (Fawcett, 1959 ; Palade, 1953). It is known that leucocytes are also able to penetrate the basement membranes, normal epithelium, and the potential spaces between cells.

The perfusion of solutions containing substances of high molecular weight breaks down to a certain degree the barrier between the capillaries and the muscle fibres of the myocardium. What these injured capillaries look like in the perfused regions and some distance from them is a subject to be investigated.

We can therefore conclude that macromolecules are able to pass across the myocardial capillary wall.

Recently, doubts have been expressed as to whether the capillary wall is a real barrier per se. Sapirstein (1959) suggests that the barrier across which the changes occur is separated by some distance from the capillary wall. He considers as a barrier the movement of materials between the capillary and the lymph as well as between the capillary and the tissue spaces. In other words, evidence of a 'haematolymph barrier' is suggested. We have in progress further studies on the permeability of the myocardial capillaries. Several interesting problems may be solved by them, for example (1) the exact route of blood drainage from different myocardial regions after perfusion of the myocardium with radioactive low molecular weight lipid soluble substances, and (2) the protective effects on the ischaemic myocardium of intramyocardially perfused dissolved oxygen in glucose under hyperbaric conditions.

\section{SUMMARY}

Particles of low molecular weight, such as glucose and urographin, as well as of higher molecular weight, such as dextran, haemoglobin, and even 
plain blood, perfused rapidly to the ventricular myocardium of beating and non-beating hearts passed easily across the myocardial capillary wall to such an extent that the regional veins were quickly distended and took the colour of the perfused fluid. Perfusion of fluorescein diluted in dextran to any region of the ventricular myocardium caused the whole heart to become fluorescent. Injection of the same amount of fluorescein in the liver of the same animals did not result in a diffusion of the fluorescent dye outside the perfused region.

\section{REFERENCES}

Anrep, G. V., Blalock, A., and Hammouda, M. (1929). The distribution of the blood in coronary vessels. J. Physiol., 67, 87.

Carton, C. A., Kessler, L. A., Seidenberg, B., and Hurwitt, E. S. (1960). Experimental studies in the surgery of small blood vessels. prosthesis and plastic adhesive. Surg. Forum, 11, 238.

Fawcett, D. W. (1959). The fine structure of capillaries, arterioles and small arteries. Ct. in the Microcirculation Symposium Univ. of Illinois Press, p. 1.

Gregg, D. E. (1950). Coronary Circulation in Health and Disease. Lea and Febiger, Philadelphia.

Herrmann, G. R. (1925). Experimental heart disease. I. Methods of dividing hearts. Amer. Heart J., 1, 213.

Landis, E. M. (1927). Micro-injection studies of capillary permeability. II. The relation between capillary pressure and the rate at which fluid passes through the walls of single capillaries. Amer. J. Physiol., 82, 217.
Martin, E. G., Wooley, E. C., and Miller, M. (1932). Capillary counts in resting and active muscles. Ibid., 100, 407.

Mautz, F. R. (1957). Anatomical and physiological considerations in the development of collateral circulation to the myocardium Dis. Chest, 31, 265.

Moore, D. H. (1959). The complexity of capillary endothelium. Ct. in the Microcirculation Symposium, Univ. of Illinois Press, p. 38

- and Ruska, H. (1957). The fine structure of capillaries and small arteries. J. biophys. biochem. Cytol., 3, 457.

Palade, G. E. (1953). Fine structure of blood capillaries. J. appl. Phys., $24,1424$.

Pappenheimer, J. R. (1953). Passage of molecules through capillary walls. Physiol. Rev., 33, 387.

- Renking, E. M., and Borrero, L. M. (1951). Filtration, diffusion and molecular sieving through peripheral capillary membranes. A contribution to the pore theory of capillary permeability. Amer. contribution to the
J. Physiol., 167, 13 .

- and Soto-Rivera, A. (1948). Effective osmotic pressure of plasma proteins and other qualities associated with capillary circulation in hindlimbs of cats and dogs. Ibid., 152, 471.

Petropoulos, P. C. (1963). Effects on cardiac function during direct perfusion of the normal or ischemic ventricular myocardium with saturated or unsaturated blood or colloidal isotonic solutions. J. thorac. cardiovasc. Surg., 46, 94.

Renkin, E. M. (1954). Filtration, diffusion and molecular sieving through porous cellulose membranes. J. Physiol., 38, 225.

- (1959). Capillary permeability and transcapillary exchange in relation to molecular size. Ct. in the Microcirculation Symposium Univ. of Illinois Press, p. 28.

Sabiston, D. C., Fauteux, J. P., and Blalock, A. (1957). An experimental study of the fate of arterial implants in the left ventricular myocardium with a comparison of similar implants in other organs. Ann. Surg., 145, 927.

Sapirstein, L. (1959). Macromolecular exchanges in capillaries. Ct. in the Microcirculation Symposium, of Illinois Press, p. 47.

Wissig, S. L (1958). An electron microscope study of the permeability of capillaries in muscle. Anat. Rec., 130, 467.

Zweibach, B. M. (1959). Structural and functional aspect of the microcirculation in the skin. Ct. in the Microcirculation Symposium Univ. of Illinois Press, p. 144. 